\title{
Design and Performance Analysis of Cross flow \& Force Draft Cooling Towers
}

\author{
Rohan Kapdi ${ }^{1}$ \\ ${ }^{1}$ Student, \\ Dept. of Mechanical Engineering, \\ BITS Pilani, Dubai, UAE
}

\begin{abstract}
Power is a substantially used in buildings in its own right, but also significantly contributes to internal heat gains. Recent advancements have allowed for higher efficiency building retrofits to be installed, yet we cannot neglect the fact that the current working practices are demanding. During the designing stage the Contractors/Consultants often rely on technological benchmarks to predict energy consumption, power demands and various other parameters such as temperature, Air quality etc. In this Project an energy \& space efficient cooling tower has been designed. Models are imported into Ansys fluent where meshing and analysis is carried out. Air inlet pipe is varied across different angles. Based on the water outlet temperature, effectives $\&$ of the different models is studied $\&$ analyzed.
\end{abstract}

Key Words: CFD, Ansys, Cross Flow Cooling Towers, Force Draft Cooling Towers.

\section{INTRODUCTION}

Presently, the O\&M (Operation \& maintenance) of the Building/Industrial facilities sector makes up as much as $40 \%$ of global energy demand as well as $40-50 \%$ of the global carbon emissions. Overall Heating Ventilation and Air Conditioning (HVAC) systems consume more than $60 \%$ of the total energy use of buildings [1].

Over the past few years due to changes in the climatic conditions, there has been very high rise and fall in the ambient temperature. According to ASHRAE, human comfort temperature range should be from 23-25 degree Celsius. To maintain this comfort temperature, air conditioning systems are used, which not only maintain the room temperature but also control various other important aspects such as comfort, like humidification, de-humidification, filtering air, controlling humidity ratio, sensible heat and latent heat and other carious parameters. In middle-east regions, such as United Arab Emirates, $70-75 \%$ of the energy produced is used for maintaining comfort temperature and the remaining is used by other HVAC equipment, and household machinery.

Geographically hot climatic conditions, such as those in Middle East countries, the percentage of energy consumption by air conditioning (AC) is significantly larger due to the more extreme conditions as the ambient temperature is comparatively higher. In Gulf Countries where the average Watt/person is $1149 \mathrm{~W} /$ person which is much higher than the world average ie. $297 \mathrm{~W} /$ person [2], the rapid growth of the development of infrastructure has increased the energy consumption at a faster rate. The solution however to this problem have been studied by the architects and building engineers.

The United Arab Emirates presently is one of the many countries which has the highest carbon footprint in step with capita in the world. The Emirate is expected to have this

\author{
Dr. Naveen Shrivastava ${ }^{2}$ \\ ${ }^{2}$ Professor, \\ Dept. of Mechanical Engineering, \\ BITS Pilani, Dubai, UAE
}

footprint even higher, having the most important economy and the best level of oil production many of the Emirates. Researcher by the name of smeetsa \& Bayar developed a model which estimates present day annual emissions of the Emirate of Abu Dhabi to be 81.Eight million tons of CO2 (fifty six\% of the total UAE emissions).

A Comprehensive Demand-Side Management Study which was established in 2009, presented the baseline for energy usage styles by using typology, zone, and purchaser segments. Figure 1 indicates the sectorial decomposition of electricity use. Commercial sector contributes to $32 \%$ whereas residential is $27 \%$. This study has developed a variety of energy performance measures and strategies which proposed many awareness on the DSM approach on Commercial, Residential and Government sectors. These sectors constitute $87 \%$ of the entire capacity \& demand load.

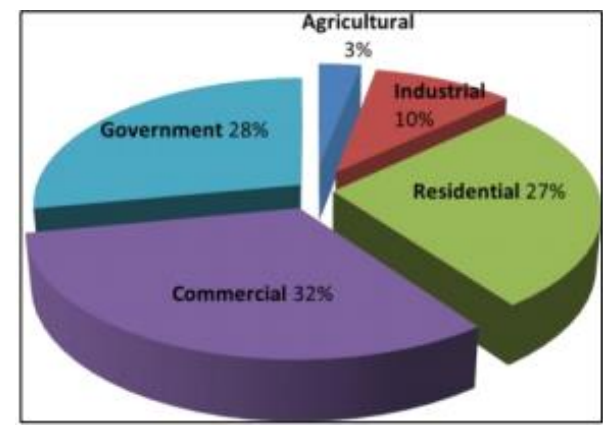

Figure 1 : Sectorial Decomposition of Electricity

Figure 2 describes the average breakdown of electricity consumption per end use according to the Ministry of energy. This breakdown depicts that HVAC components consume over $70 \%$ of the total electricity consumption

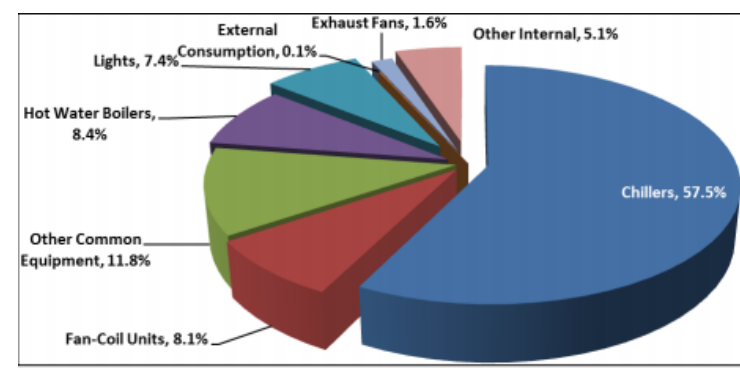

Figure 2: Average Breakdown of Electricity

\subsection{Energy Issue}

The ever increasing energy consumption has also raised issues about the availability, exhaustion of resources and environmental depletion, climatic changes and global warming. To reverse this case many measures are studied. The Kyoto 
protocol was one of the very first agreement planned in order to regulate this situation on a global scale.

The 20-20-20 consists of an emissions and renewables goal which is legally binding at the same time as the power saving target isn't always. The Europe 2020 technique which could help sell efficiency and a sustainable boom time table must now not be used to update national goals and plans, especially at a time whilst more transparency, comparability and commitment is required .New trends try to preserve the carried out present day satisfactory of existence fashion even as lowering the extent of power used.

\subsection{Role of HVAC Consumption in United Arab Emirates}

UAE has one of the maximum power consumption in step with capita within the international. This reflects negatively at the $\mathrm{CO} 2$ emissions that's an growing determination inside the UAE. CO2 emissions should be decreased as part of the global attempt to reduce the greenhouse gases and mitigate global warming outcomes. This observe ambitions to lessen the energy consumptions within the federal buildings inside the UAE[3].

This studies used to find the pleasant lighting and manage technologies that may be used in Federal Buildings in UAE to lessen the full strength intake through decreasing lighting electricity intake as an instantaneous strength and also the HVAC (cooling) electricity that is the oblique power that can be stored depending on saving in lighting electricity.

The outside temperature in this location can exceed $50{ }^{\circ} \mathrm{C}$ inside the summer time which results in wasting large amounts of power due to multiplied cooling and light's needs. In the closing decade, investigators conducted diverse researches that intention to gain citizens consolation even as reducing strength consumption.

Furthermore, resulting from the building energy needs, Figure 5 depicts that HVAC systems accounts for around $65 \%$ of the building energy needs. Lighting systems accounts for $13 \%$ \& pumping system accounts for $9 \%$.

\section{Typical Energy Use Break Down}

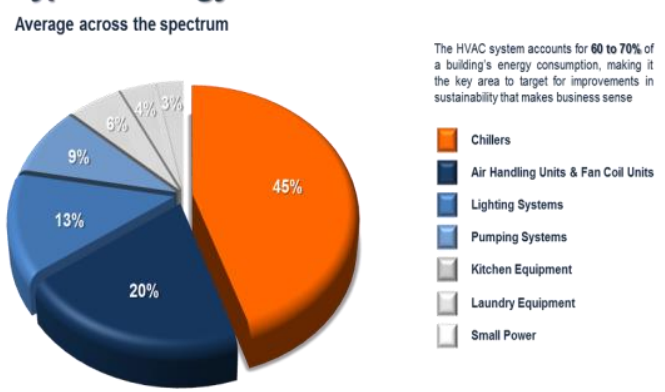

Figure 3 : Typical Energy Consumption Breakdown

\section{LITERATURE REVIEW}

There are several work inside the literature that look at the additives formerly cited to assess their influence on the cooling tower thermal performance. Regarding the fill, Thomas and
Houston [4] and Lowe and Christie[5] evolved warmth and mass transfer correlations the usage of cooling towers outfitted with one of a kind styles of fill. Kelly and Swenson[6] studied the heat transfer and stress drop characteristics of a touch grid form of cooling tower fill. These authors concluded that the homes and geometry of the fill have an effect on the tower function cost thru correlations with the water to air mass waft ratio.

Goshayshi and Missenden[7] experimentally studied the mass transfer and the stress drop characteristics of smooth and difficult floor corrugated fill in atmospheric cooling towers. As written by Battle Mccarthy, traditionally, wind catchers also known as wind catchers were used in middle-east for cooling air entering into the room to certain extent. They were known by different names in different areas of middle-east. "Hughes et al conducted research on cooling techniques for wind tower, for different uses. This included parameters like rate of variation, temperature, and velocity. These parameters were studied to see the viability of wind tower for respective use. The results obtained showed $12-15 \mathrm{k}$ reduction in temperature. Jones and Kirby explained the structure and design of wind tower.

Furthermore, Bouchahm et al focused his research on thermal efficiency of wind tower. He showed that wetted internal columns of wind tower resulted in $2-3 \mathrm{~K}$ extra reduction in temperature. Badran using mathematical model, Badran conducted study on multi-directional wind tower. And its effect on ventilation output. Elmualim et al studied effect of shape and structure of wind tower on its efficiency.

$\mathrm{He}$ experimented with square and circular type of heat exchanger. Results concluded that square shaped wind catchers are more efficient than circular one.

\subsection{Cooling Towers}

Cooling towers are an essential element of many refrigeration structures, supplying cooling across a huge range of applications. They are the point within the system in which heat is dissipated to the environment through the evaporative process, and are not unusual in industries together with oil refining, chemical processing, power flora, metal generators, and lots of distinctive production tactics in which procedure cooling is needed. They are also normally used to provide consolation cooling for large commercial buildings consisting of airports, workplace homes, conference centers, hospitals, and lodges. Most air-conditioning systems and commercial process generate heat that need to be removed and dissipated. Water is commonly used as a heat transfer medium to remove the heat generated from refrigerant condensers. In the past, this was carried out by using water received from utility water supply/natural body \& then heating it as it passes through it , after which discharging the water directly to a sewer or returning it to the body of water.

Water bought from industrial process for this purpose has now turn out to be considerably pricey because of improved water deliver and disposal prices. Similarly, cooling water drawn from sources is quite unavailable due to the fact the ecological disturbance resulting from the accelerated temperature of 
discharge water has grow to be unacceptable. Air-cooled heat exchangers cool water via rejecting heat immediately to the atmosphere, however the first value and fan consumption of these gadgets are high and the location required is fantastically huge. They can economically cool water to within about $20^{\circ} \mathrm{F}$ of the ambient dry-bulb temperature-too excessive for the cooling water requirements of maximum refrigeration systems and many business strategies.

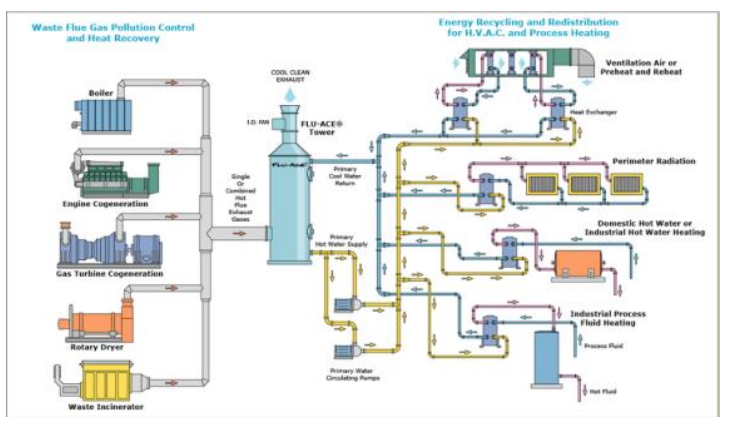

Figure 4 : Typical Heat Rejection System in Industries

In many big manufacturing industries, a wet scrubber was used for heat recovery, and as such it can accept a very wide variety of process exhausts as heat sources. With natural gas boiler exhausts the system is effectively bulletproof, with a lifespan of over 30 years. FLU-ACE can also be applied to reciprocating engine and gas turbine exhausts, oil boilers, biomass boilers, pulp and paper and tissue machine dryer section exhausts, smelt dissolving tank exhausts, food and beverage process steamer, cooker, and fryer exhausts, evaporators, sterilizers, casting oven exhausts, incinerators / oxidizers, and more. Whatever your heat source is, if you can provide information about the source, Thermal Energy can advise as to the suitability of the FLU-ACE and other heat recovery options.

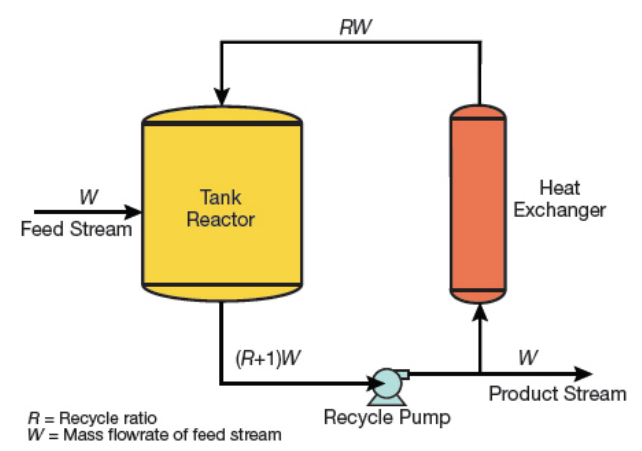

Figure 5 : Heat Exchanging in Chemical Plants

\subsection{Working Principle}

A cooling tower cools water with by heat and mass transfer principle. Water to be cooled is sent inside the tower through spray nozzles, splash bars, or movie-type fill, which exposes a very large water floor vicinity to atmospheric air. Atmospheric air is circulated by Fan/currents (natural/convective) or induction impact from sprays. A part of the water absorbs heat to exchange from a liquid to a vapor at regular strain. This heat of vaporization at atmospheric strain is transferred from the water closing in the liquid nation into the airstream. Figure 9 indicates the temperature relationship among water and air as they skip through a counter flow cooling tower. The curves indicate the drop in water temperature (A to $\mathrm{B}$ ) and the rise in the air wet-bulb temperature (C to $D)$ of their respective passages through the tower. The temperature distinction between the water entering and leaving the cooling tower (A minus $\mathrm{B}$ ) is the range

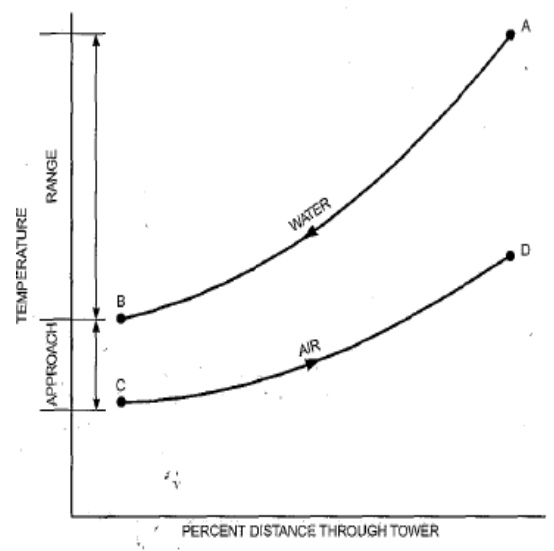

Figure 6 : Temperature relationship among Water and Air

The difference between the leaving water temperature and entering air wet-bulb temperature' (B minus C) in Figure 9' is the approach to the wet bulb or simply the approach of the cooling tower. The approach is the function of cooling tower capability, and a larger cooling tower produces a closer approach (colder leaving water) for a given heat load, flow rate, and entering air condition.

Thus, the amount of heat transferred to the atmosphere by the cooling tower is always equal to the heat load imposed on the tower, whereas the temperature level at which the heat is transferred is determined by the thermal capability of the cooling tower and the entering air wet-bulb temperature.

The thermal capability of a cooling tower used is regularly expressed in nominal cooling tower heaps. A nominal cooling tower ton is described as cooling $3 \mathrm{GPM}$ of water from $95^{\circ} \mathrm{F}$ to eighty $5^{\circ} \mathrm{F}$ at a $78^{\circ} \mathrm{F}$ entering air moist-bulb temperature. At those situations,

The cooling tower rejects $15,000 \mathrm{Btu} / \mathrm{h}$ per nominal cooling tower ton. The historical derivation of this $15,000 \mathrm{Btu} / \mathrm{h}$ cooling tower ton, as compared to the $12,000 \mathrm{Btu} / \mathrm{h}$ evaporator ton, is based on the idea-that at ordinary air-conditioning conditions.

For every $12,000 \mathrm{Btu} / \mathrm{h}$ of warmth picked up in the evaporator, the cooling tower ought to burn up an additional $3000 \mathrm{Btu} / \mathrm{h}$ of compressor warmness. For particular programs, however, nominal tonnage ratings aren't used, and the thermal performance capability of the tower is normally expressed as a price at specific operating temperature conditions 


\subsection{Types of Cooling Tower}

Cooling tower are designed \& manufactured in different types with many models, sizes. Now not all types are suitable for every application to heat load every application. Here are the different types of cooling towers:

\section{Atmospheric Towers}

Atmospheric towers requires no fans in order to create an air flow through the tower. It derives its air from natural aspiration provided by a special pressure spray induced system.

Although It is relatively inexpensive, but is usually used in small applications. However since it requires cold water temperature to be maintained it is not recommended for industrial applications.

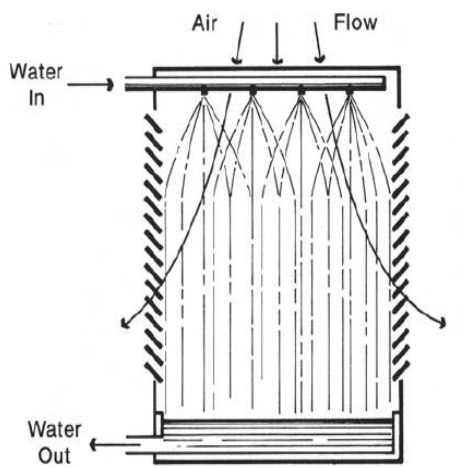

Figure 7: Atmospheric Cooling Tower

\section{MECHANICAL DRAFT TOWERS}

Mechanical Draft towers use single/multi fans in order to provide a fixed volume of air through the tower. Due to this their thermal performance is more stable and is affected by fewer psychometric parameters when compared to atmospheric towers. They are further subdivide into forced draft $\&$ induced draft towers.

Forced draft have the fans located in the ambient air stream entering tower and then the air is blown through he tower. They are categorized by high inlet air velocities \& low exit air velocities. However they are extremely prone to recirculation and therefore are less efficient than induced draft towers.

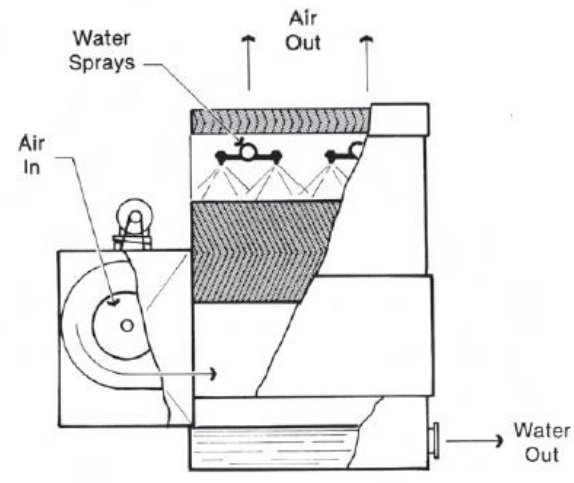

Figure 8: Force Draft Cooling Tower

In Induced draft towers, fans are located in air stream which draws the air through the water. Induced draft towers have air discharge velocities from 3-4 times higher than forced draft making them more performance efficient.

Location of the fans within the flow of the air stream provides an excellent protection against the formation of any ice particles in the mechanical components.

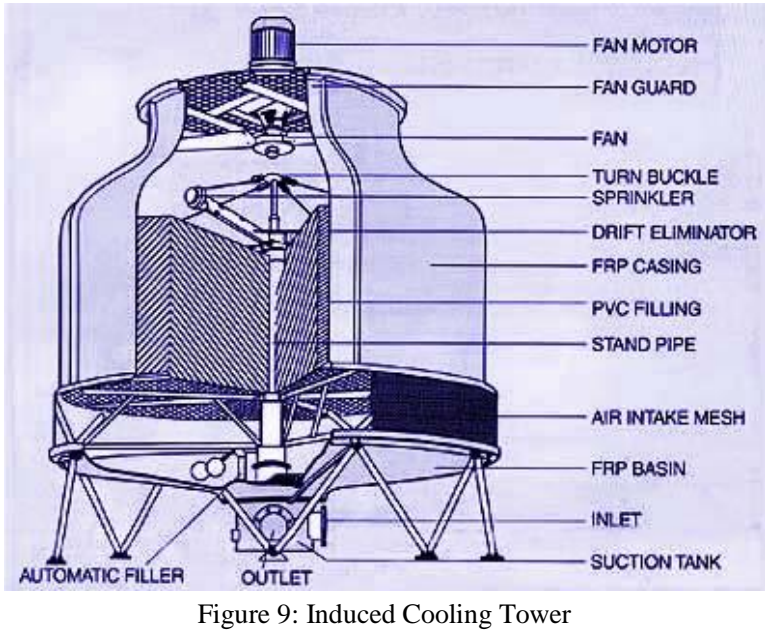

Cooling towers are also categorized by the type of air flows. They are:

\section{Counter Flow Towers:}

As the name suggests, in counter flow towers the air flows vertically upward through the fill $\&$ the water flows vertically downward. No because of the need to have more intake \& discharge air surface, some of the smaller counter flow devices require more pump head, more fan power than cross flow towers. The only disadvantage of using a counter flow towers are that enclosed nature restricts exposure to water to direct sunlight.

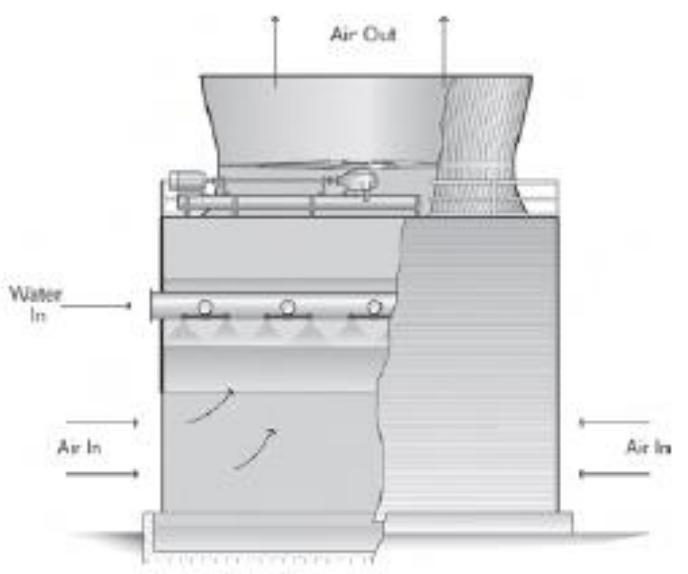

Figure 10: Counter Flow Cooling Tower

Cross Flow Towers:

Cross flow towers have a fill configuration in which the air flows horizontally across the downward flow of water. Water which is to be cooled passes through the hot water basin and is distributed to the fill by gravity through metering orifices which are located in the fill of the basins. Due to this system 
the need for a pressure bases spray system is must, also the proper utilization of flow control valves.

Because air velocities for the vertical spray tower (both entering and leaving) are relatively low, such towers are susceptible to adverse wind effects and, therefore, are normally used to satisfy a low-cost requirement when operating temperatures are not critical to the system[21]. Some horizontal spray towers use high pressure sprays to induce large air quantities and improve air water contact (as in Figure 15). Multispeed staged pumping systems are normally recommended to reduce energy use in periods of reduced load and ambient conditions.

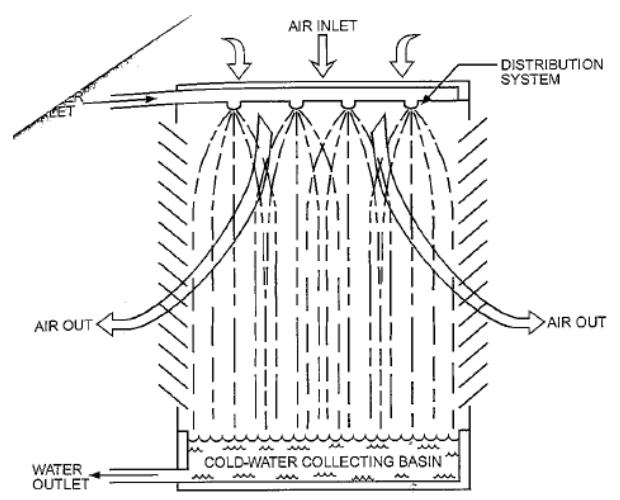

Figure 11: Vertical spray Tower

\subsection{Cooling Tower Fills}

The heart of the cooling tower are the fills. They are a medium used in cooling towers to broaden the surface discipline of the tower. Improved surface subject enables for highest contact between the air and the water, which allows for bigger evaporation premiums.

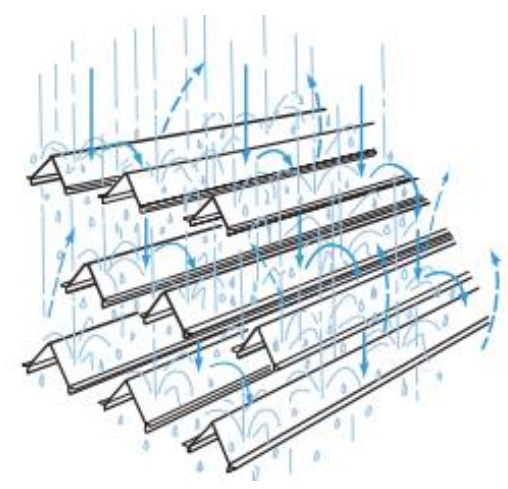

Figure 12: Cooling Tower Fills

There are two normal types of fill: Splash fill and film fill. Splash fill is designed to interrupt the water and purpose splashing. Film fill, however, is made up of sheets of material that the water travels throughout. Pieces of fill are assembled together to create higher blocks which, in flip, are used to create more than a few thickness and heights to suit the particular cooling tower they're going to be used for.

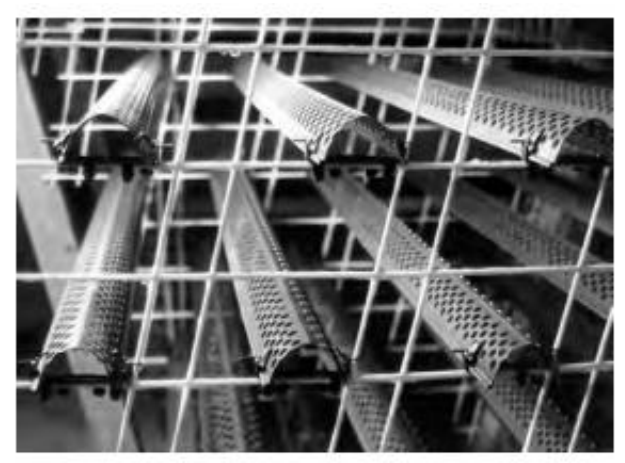

Figure 13: Splash Fill

\section{DESIGN \& MESHING OF COOLING TOWER}

The Cooling Tower Model has been modelled by using Catia Software. For this Project 2 designs have been chosen.

\section{Design 1 - Forced Draft Cooling Tower.}

The below designed model have the following dimensions:

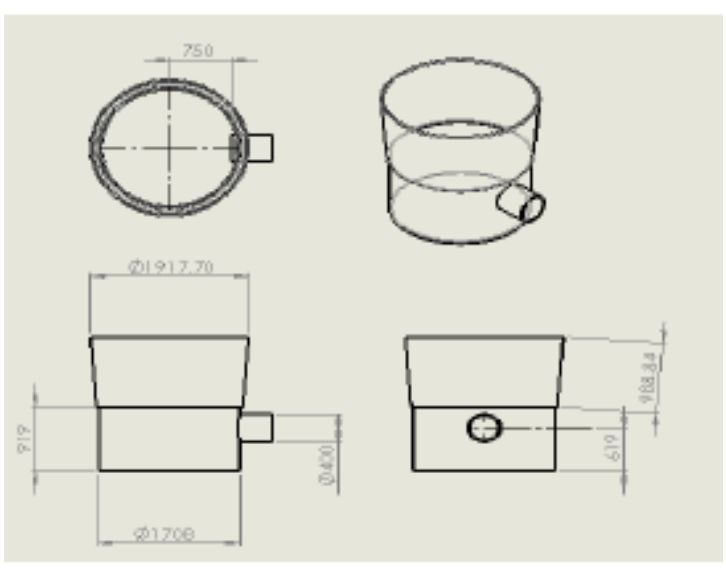

Figure 14: Forced Draft Cooling Tower Dimension

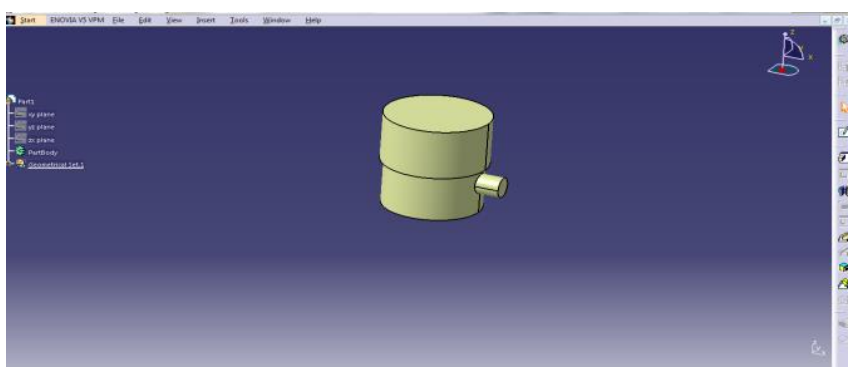

Figure 15: Cooling Tower Dimensions \& Design

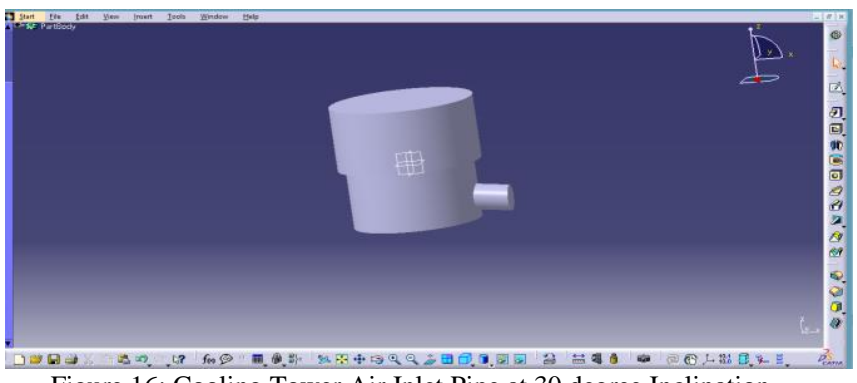

Figure 16: Cooling Tower Air Inlet Pipe at 30 degree Inclination 


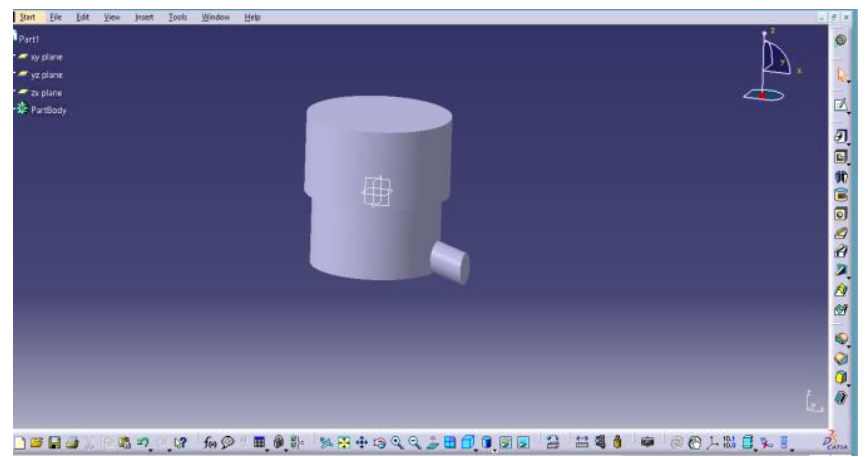

Figure 17: Cooling Tower Air Inlet Pipe at 60 degree Inclination

Meshing - Forced Draft Cooling Towers

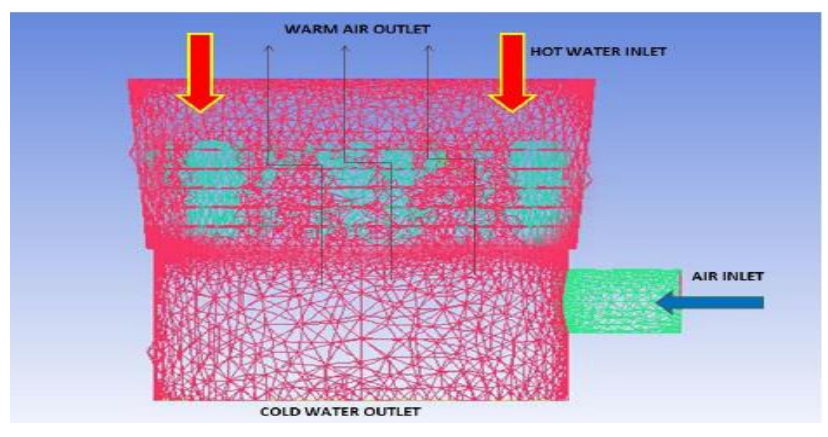

Figure 18: Meshing

Design 2 - Cross Flow Cooling Tower.

The below designed model have the following dimensions:

\begin{tabular}{|c|l|l|l|l|}
\hline \multirow{2}{*}{$\begin{array}{c}\text { Designed } \\
\text { Tons }\end{array}$} & \multicolumn{4}{|c|}{ Dimensions ( m) } \\
\cline { 2 - 5 } & L & W & H & S \\
\hline $110-120$ & 3.04 & 2.13 & 2.9 & 2.6 \\
\hline
\end{tabular}

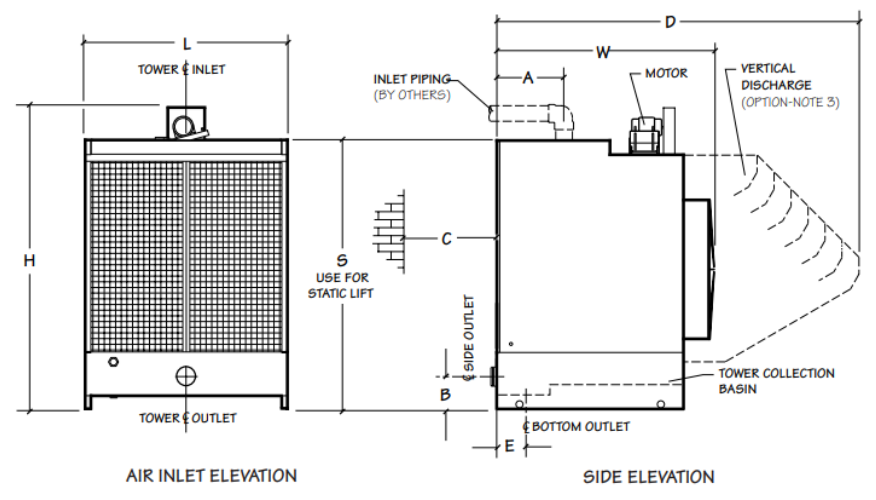

Figure 19: Cross Flow Cooling Tower Dimension
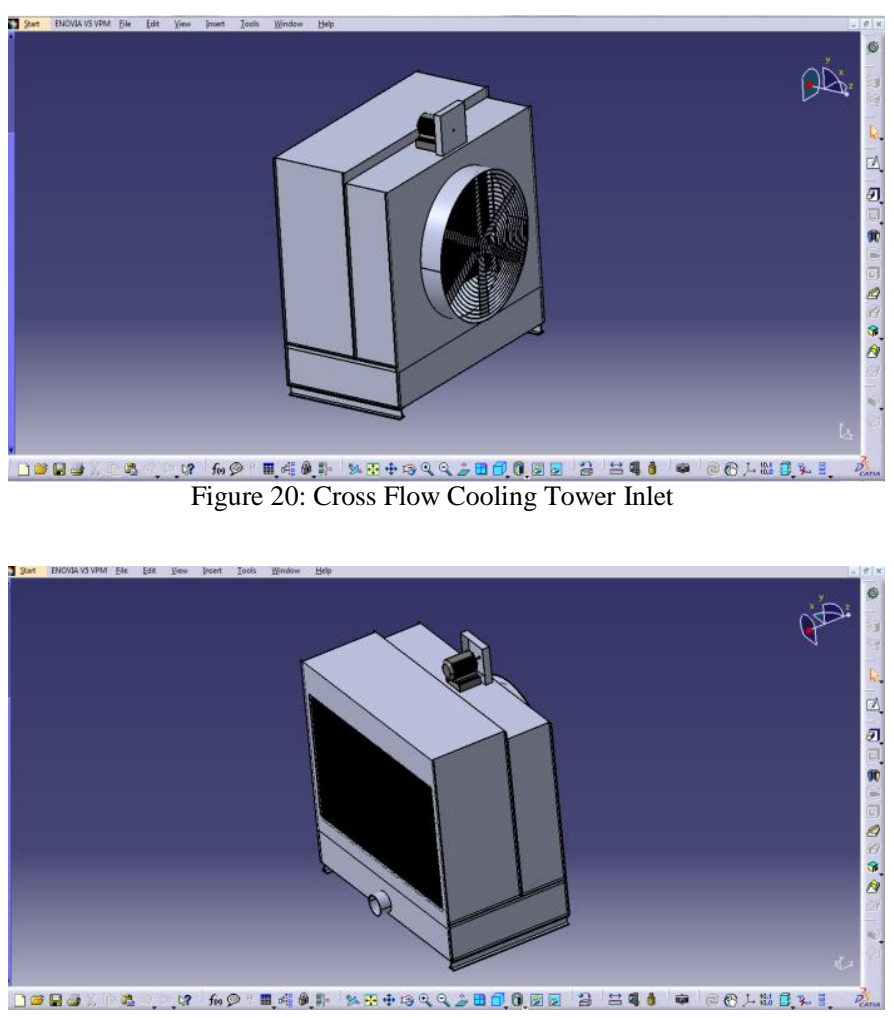

Figure 21: Cross Flow Cooling Tower Outlet

Meshing - Cross Flow Cooling Towers

This cooling tower model has been saved as an IGES (Initial Graphics Exchange Specification) format. It has then been imported into Ansys. Then the models have been meshed by using the Ansys CFD (Fluent) Software. For improved element quality, the Tetra mesher was incorporated for improved meshing size

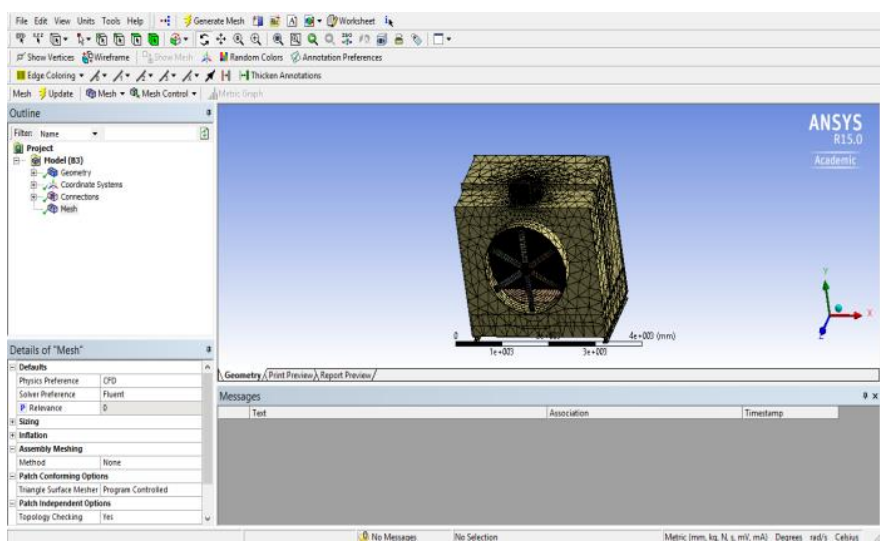

Figure 22: Cross Flow Cooling Tower Inlet Meshing 


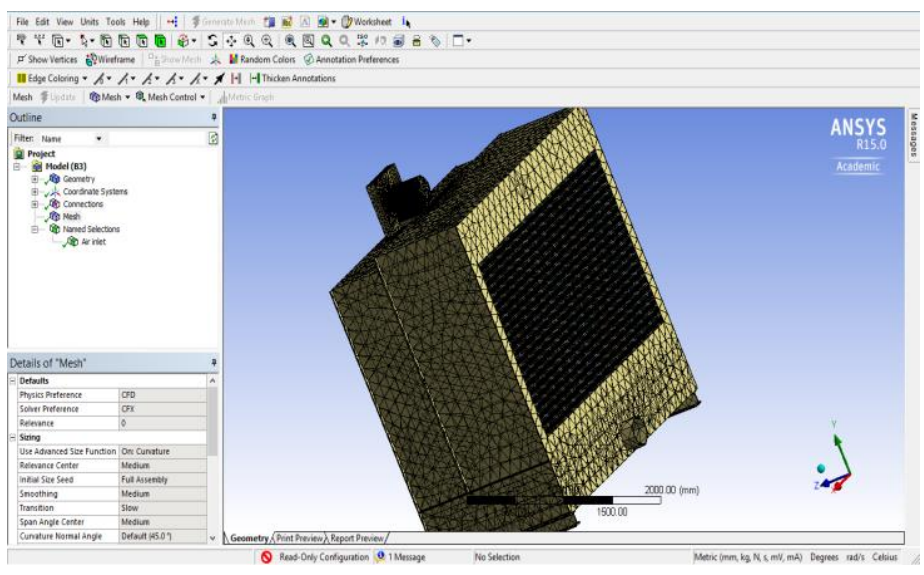

Figure 23: Cross Flow Cooling Tower Outlet Meshing

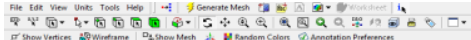

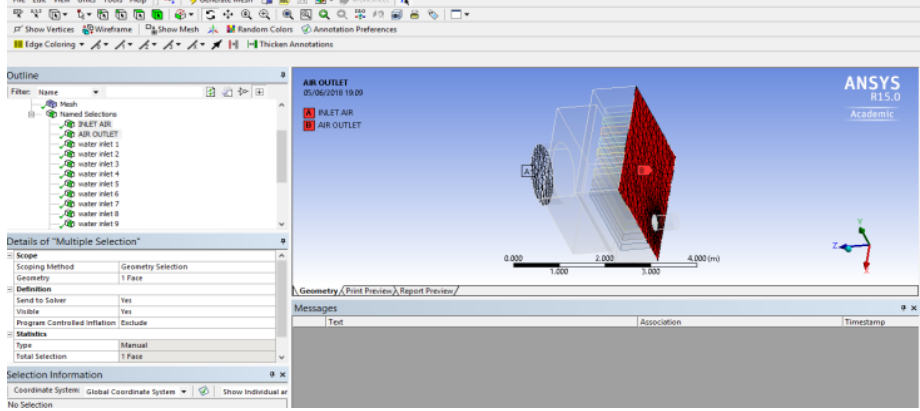

Figure 24: Air Inlet \& Outlet Boundary Conditions

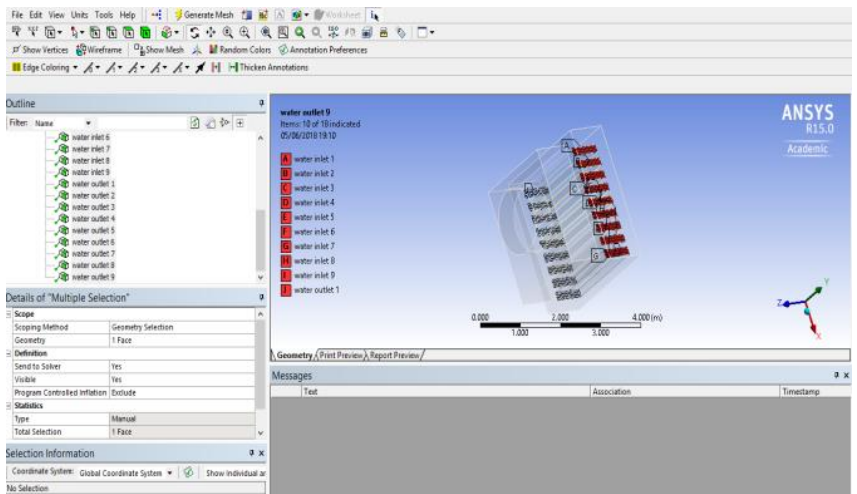

Figure 25: Water Inlet \& Outlet Boundary Conditions

\section{RESULTS}

Design 1 \& 2 models were solved by applying boundary conditions, the solution is initialized and the temperature contours obtained after the solution convergence criteria get reached up to its minimum value. However Design 2 could not be analyzed at a grated scale due to technical difficulties \& lack of resources.
Design 1 was analyzed \& the results are as below:

1. Cooling Tower Air Inlet Pipe @ 0 Degree

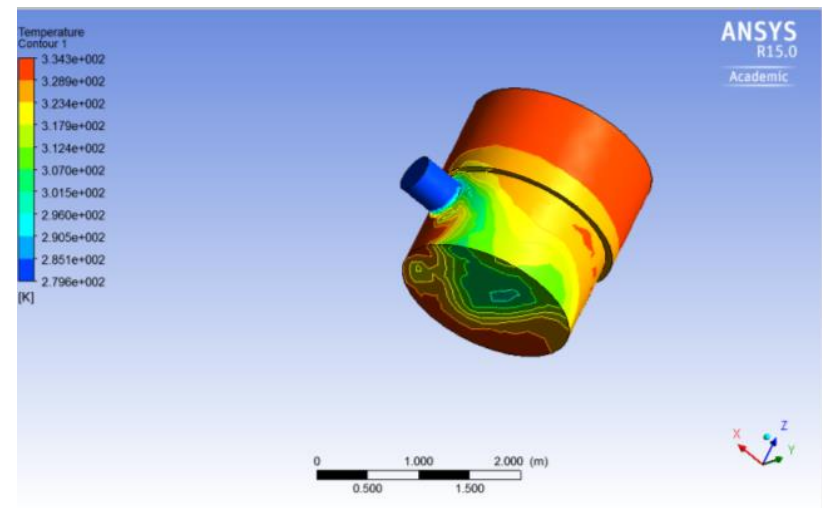

Figure 26: Front View @ 0 Degree Inclination

2. Cooling Tower Air Inlet Pipe @ 30 Degree

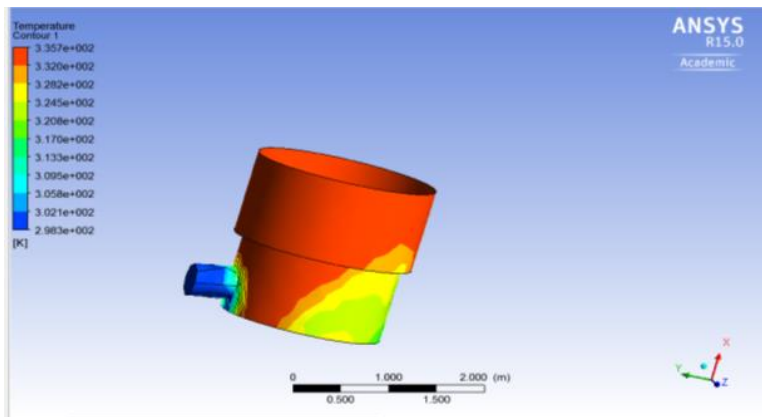

Figure 27: Front View @ 30 Degree Inclination

3. Cooling Tower Air Inlet Pipe @ 60 Degree

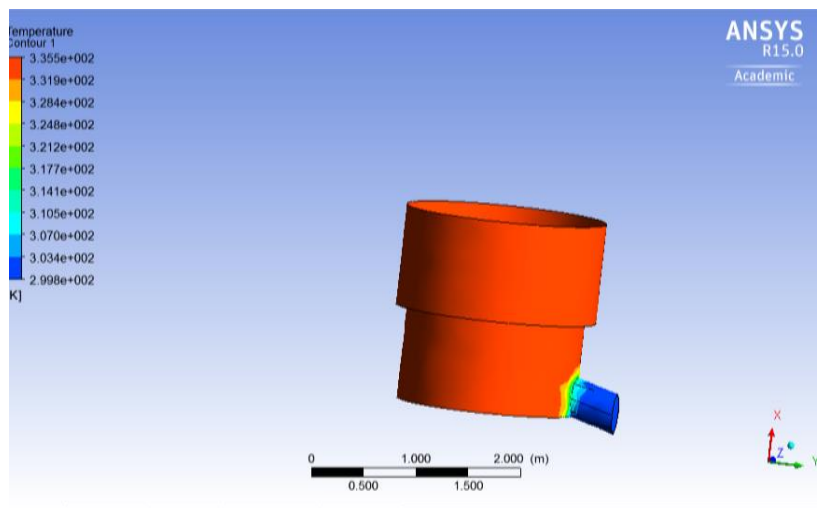

Figure 28: Front View @ 60 Degree Inclination

\section{RESULTS \& CONCLUSION}

The below table shows the air \& water inlet /outlet temperatures and their respective effectiveness. 


\begin{tabular}{|r|r|r|r|r|r|}
\hline Model & $\begin{array}{c}\text { Air Inlet } \\
\text { Temp. } \\
(\mathrm{K})\end{array}$ & $\begin{array}{c}\text { Water } \\
\text { Inlet } \\
\text { Temp. } \\
(\mathrm{K})\end{array}$ & $\begin{array}{c}\text { Water } \\
\text { Outlet } \\
\text { Temp. } \\
(\mathrm{K})\end{array}$ & Range (K) & $\begin{array}{c}\text { Effective-ness } \\
(\%)\end{array}$ \\
\hline I & 300 & 335 & 307 & 28 & 80 \\
\hline II & 300 & 335 & 309 & 26 & 74.28 \\
\hline III & 300 & 335 & 317 & 18 & 51.4 \\
\hline
\end{tabular}

Model I - Air Inlet Pipe at $0^{\circ}$

Model II - Air Inlet Pipe at $30^{\circ}$ Inclination

Model III - Air Inlet Pipe at $60^{\circ}$ Inclination

Hence the evaporation rate characteristic between air \& water have been varied for cooling tower models due to the change ink contact surface of air and water which have been caused by varying air inlet angles.

It has been shown that; Ansys Fluent software can be used for performance and analysis of cooling tower. A Cooling Tower is used to reduce the temperature of hot fluid stream. It is mainly used in air conditioning plant, Chemical Plants etc. The design of cooling tower is closely related to tower characteristics and different types of losses generated in cooling tower.

In this report, 3 different types of cooling tower models are compared. The cooling tower with air inlet pipe at $0^{\circ}$ has the highest effectiveness of $80 \%$ and the cooling tower with air inlet pipe inclined at $30^{\circ}$ have an effectiveness of $74 \%$. However when the air inlet angle was kept at $60^{\circ}$ angle the effectiveness dropeed to $51.4 \%$.

Evaporation loss and Effectiveness are two important performance parameters of Cooling Tower.Water outlet temperature of cooling towerl increases as the air inlet angle increases. Hence the coolingkefficiency and effectiveness of cooling tower decreases. This concludes that these cooling tower models can be validated experimentally and can be installed for a small scale industries.

\section{REFERENCES}

[1] Mohamad Monkiz Khasreen 1, Phillip F.G. Banfill 2,* and Gillian F. Menzies 3 Life-Cycle Assessment and the Environmental Impact of Buildings: A Review sustainability ISSN 2071-1050.

[2] Alnaser, W.E. \& Alnaser, N.W., 2011. "The status of renewable energy in the GCC countries," Renewable and Sustainable Energy Reviews, Elsevier, vol. 15(6), pages 3074-3098, August.

[3] Aidyn Bibolov, Selim Cakir, Pilar Garcia Martinez, Mauricio Soto, and Natalia Tamirisa ENHANCING MEDIUM-TERM FISCAL POLICY FRAMEWORK: KEY IMPERATIVE FOR THE UAE International monetary fund, July 2017.

[4] W.J. Thomas, P. Houston, Simultaneous heat and mass transfer in cooling towers. Brit. Chem. Eng, 1959, 160-217.

[5] H.J. Lowe, D.G. Christie, Heat transfer and pressure drop data on cooling tower packings, and model studies of the resistance of natural draft towers to air flow, Inst Mech Eng (Steam Group) Symposium on Heat Transfer, 1962, 113-933. 